\title{
TIN WHISKER FORMATION ON SMALL OUTLINE TRANSISTORS ASSEMBLED USING BISMUTH-CONTAINING LEAD-FREE SOLDER ALLOYS AFTER LONG- TERM AMBIENT TEMPERATURE, HIGH HUMIDITY STORAGE PART 2: STATISTICAL ANALYSIS
}

\author{
André M. Delhaise', Stephan Meschter², Polina Snugovsky', Jeff Kennedy'", Zohreh Bagheri' \\ ${ }^{1}$ Celestica Inc., Toronto, ON, Canada \\ ${ }^{2} B A E$ Systems, Endicott, NY, USA
}

\begin{abstract}
With the introduction of environmental legislation such as the Restriction of Hazardous Substances (RoHS), lead (Pb)-free materials have made their way into the electronics manufacturing industry. One issue that has emerged is that $\mathrm{Pb}$-free solder alloys can initiate and grow tin whiskers under specific conditions. These whiskers are thin, highly conductive filaments which have the potential to grow and can cause field failures in many applications. Most concerning with respect to tin whiskering are high reliability applications such as aerospace, automotive, and medical.

Bismuth (Bi) is being considered for inclusion in solder alloys to replace the current industry standard (SAC 305) and provide improved thermomechanical and vibration reliability. In this paper, we discuss whisker formation of several Bi-bearing alloys after long-term (12,000 hours), ambient high humidity $\left(25^{\circ} \mathrm{C} / 85 \%\right.$ $\mathrm{RH})$ storage. Three alloys containing $\mathrm{Bi}$, in addition to SAC 305 (Sn-3.0Ag-0.5Cu), were considered. These alloys were Violet (Sn$2.25 \mathrm{Ag}-0.5 \mathrm{Cu}-6.0 \mathrm{Bi})$, Sunflower $(\mathrm{Sn}-0.7 \mathrm{Cu}-7.0 \mathrm{Bi}$ ), and Senju (Sn2.0Ag-0.7 (Cu-3.0Bi). The boards were fabricated with electroless nickel immersion gold (ENIG) and immersion tin (ImmSn) finishes and populated with parts having $\mathrm{Cu}$ and Fe42Ni alloy leads and chip parts, with half of assemblies cleaned and half cleaned and contaminated with low levels of $\mathrm{NaCl}$.
\end{abstract}

This paper is the second in a series of three in which we share quantitative statistical analysis from the whisker inspection of the small outline transistor (SOT) components. It was found that on ImmSn surface finishes, the longest whiskers were found on SAC, however the longest whiskers were found on Bi-bearing alloys for ENIG. In addition, whiskers were found to generally grow in regions where the tin coverage is thin, and, on ENIG-finished assemblies, near the PCB, likely due to galvanic corrosion between the solder and the finish chemistry.

Keywords: Tin whisker, nucleation, growth, corrosion, ambient temperature, high humidity, lead-free solder, bismuth, SAC

\section{BACKGROUND}

The elimination of lead $(\mathrm{Pb})$ from consumer electronics has resulted in an increased emphasis on tin whisker risk mitigations in aerospace and defense systems using dual-use commercial/ aerospace components [1]. Environmental prohibitions of lead in commercial electronics have made these electronic parts and assemblies become more susceptible to tin whiskering. Tin whisker shorting issues were known to be an issue decades ago and at that time whisker issues were solved by the addition of lead into tin. Unlike consumer electronics, aerospace systems can have high consequences of failure and are exposed to many kinds of environmental conditions that promote whisker growth. Some conditions of concern are thermal cycling, vibration, shock, humidity, salt fog, sulfur rich environments, rework, and long term storage. Figure 1 shows several sources of compressive stress in a typical tin plated lead and solder joint.
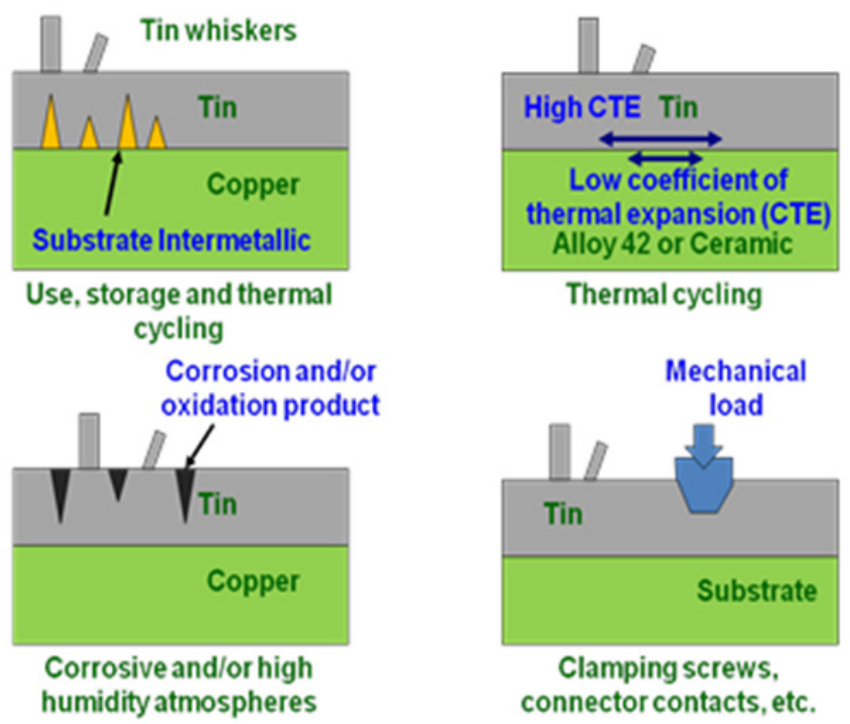

Figure 1: Sources of compressive stress contributing to whisker growth.

The dynamic recrystallization model provides a useful means to describe whisker growth [2]. An interesting aspect of the dynamic recrystallization model is that for a given temperature and grain size if the compressive stress in the tin is either too low or too high, whisker growth does not occur.

Although lead has demonstrated effectiveness at reducing whisker propensity, tin alloying elements can either increase or decrease whisker growth in Sn plating [3][4]. A short duration Sn plating study indicated that $\mathrm{Bi}$ addition tended to retard whisker growth 
[5]. However, prior soldered assembly tin whisker testing revealed that the entire material system of the lead-free solder joint must be considered when evaluating tin whisker growth (e.g. lead material, lead finish, solder alloy, board pad finish, board pad material, and the type/location of intermetallics within the joint) [6]. Solder can have significant whisker growth due to corrosion between different intermetallics in the alloy when contamination is present [7]. The whisker propensity of bismuth containing lead-free alloys in the present evaluation is a lower stress longer term evaluation than the previously completed high temperature high humidity testing [8] [9]. Here an $25^{\circ} \mathrm{C} / 85$ percent relative humidity environment is used, similar to the soldered assembly tin whisker growth test previously performed on SAC305 (Sn-3.0Ag-0.5Cu) [10]. This paper is the second of three parts detailing statistical analysis of whisker growth on the same small outline transistor (SOT) components assembled using bismuth-containing solder alloys shown in the previous paper.

\section{METHODOLOGY}

\section{Test Vehicle, Assembly, Cleaning, Contamination, and Exposure}

Custom test vehicles were used for whisker growth testing. The individual printed circuit boards (soldered twelve at a time on a panel) are $6 \mathrm{~cm} \times 6 \mathrm{~cm} \times 2.36 \mathrm{~mm}$ thick double sided glass epoxy with one ounce copper external base layers and finished with either immersion tin (ImmSn) or immersion gold over electroless nickel (ENIG), both in accordance with IPC-6012.

The types of test vehicles were assembled: SOT (small outline transistor), QFP (quad flat pack) and BGA/CAP (ball grid array/ capacitor). Only the SOT boards (Figure 2) are considered in this paper; part types on this test vehicle are given in Table 1. The boards on the panels were soldered using solder pastes composed of the alloys and flux shown in Table 2. The SAC305 assemblies were soldered with a peak reflow temperature of $240{ }^{\circ} \mathrm{C}$, while the bismuth containing alloys had a peak reflow temperature of 226 to $228^{\circ} \mathrm{C}$ (as measured at the board surface).

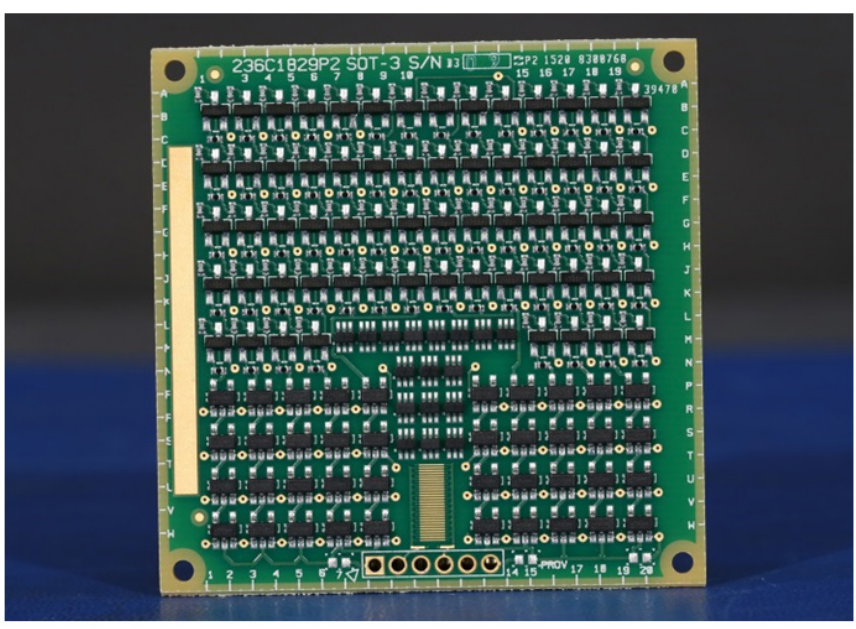

Figure 2: SOT test vehicle.
After soldering, the boards were cleaned with a conventional in-line cleaner. Next, selected boards were re-contaminated by immersion in pans with solution of $160 \mathrm{ppm} \mathrm{NaCl}$ in deionized water. Based on prior work, the resulting assembly contamination level of the purposely contaminated assemblies is expected to be near 5 ppm Cl- by ion chromatography with a total concentration of approximately $12 \mu \mathrm{g} /$ in $^{2}$ equivalent $\mathrm{Cl}$ - as measured by resistivity of solvent extraction [10]. Assemblies were exposed to low temperature high humidity $(\mathrm{ATHH}) 25^{\circ} \mathrm{C} / 85^{\circ} \%$ relative humidity (RH) simulated long term storage.

Table 1: SOT board parts.

\begin{tabular}{|c|c|c|c|}
\hline $\begin{array}{c}\text { Designation } \\
\text { Part No. Package }\end{array}$ & $\begin{array}{c}\text { Lead } \\
\text { Frame (4) }\end{array}$ & $\begin{array}{l}\text { Lead } \\
\text { finish }\end{array}$ & $\begin{array}{c}\text { No. of leads per part } \\
\text { / No. of parts }\end{array}$ \\
\hline $\begin{array}{c}\text { SOT3 } \\
\text { 2N7002 (1) } \\
\text { SOT23-3 }\end{array}$ & Alloy 42 & $\begin{array}{l}\text { Matte } \\
\text { Sn }\end{array}$ & $3 / 64$ \\
\hline $\begin{array}{c}\text { SOT5 } \\
\text { NC7S08M5X (2) } \\
\text { SOT23-5 } \\
\end{array}$ & $\mathrm{Cu} 194$ & $\begin{array}{l}\text { Matte } \\
\text { Sn }\end{array}$ & $5 / 40$ \\
\hline $\begin{array}{c}\text { SOT6 } \\
\text { 2N7002DW-7-F } \\
\text { (1) SOT363 }\end{array}$ & Alloy 42 & $\begin{array}{l}\text { Matte } \\
\text { Sn }\end{array}$ & $6 / 17$ \\
\hline $\begin{array}{c}\text { R0402 } \\
\text { 0402- Pb-free } \\
\text { Chip resistor }\end{array}$ & Alumina & $\begin{array}{l}\text { Matte } \\
\text { Sn }\end{array}$ & $2 / 128$ \\
\hline \multicolumn{4}{|c|}{$\begin{array}{l}\text { Notes: (1) Fairchild; (2) Diodes Inc.; (3) Practical Components } \\
\text { (Amkor); (4) From the manufacturer's data sheet Alloy } 42 \text { is } \\
\text { Fe39-41Ni-0.6Mn-0.05Cr-0.02Si-0.05C and Cu194 alloy is } \mathrm{Cu} \\
2.1-2.6 \mathrm{Fe} 0.015-0.15 \mathrm{P} 0.05-0.2 \mathrm{Zn}\end{array}$} \\
\hline
\end{tabular}

Table 2: Solder assembly alloys and fluxes.

\begin{tabular}{|c|c|c|}
\hline Solder & $\begin{array}{c}\text { Composition } \\
\text { (weight percent) }\end{array}$ & Flux \\
\hline SAC305 & $96.5-\mathrm{Sn}, 3-\mathrm{Ag}, 0.5-\mathrm{Cu}$ & INDIUM8.9HF \\
\hline Senju M42 & $\begin{array}{r}94.25-\mathrm{Sn}, 2-\mathrm{Ag}, 0.75-\mathrm{Cu}, \\
3-\mathrm{Bi}\end{array}$ & INDIUM8.9HF \\
\hline Sunflower & $92.3-\mathrm{Sn}, 0.7-\mathrm{Cu}, 7-\mathrm{Bi}$ & INDIUM8.9HF \\
\hline Violet & $\begin{array}{r}91.25-\mathrm{Sn}, 2.25-\mathrm{Ag}, 0.5- \\
\mathrm{Cu}, 6-\mathrm{Bi}\end{array}$ & INDIUM8.9HF \\
\hline
\end{tabular}

For further details concerning these processes, please refer to the corresponding section(s) in Part 1 of this paper series.

\section{Whisker Inspection}

A Hitachi S-3000 scanning electron microscope (SEM) was used for the inspection and an electron dispersive X-Ray (EDX) was used for elemental analysis. The first inspection was performed after 1,000 hours. Following the inspection, the samples returned into the chamber and re-inspected after an additional 3,000 hours for a total of 4,000 hours $(1,000 \mathrm{~h}+3,000 \mathrm{~h})$. Then the samples were returned to the chamber again and re-inspected after an additional 8,000 hours for a total of 12,000 hours $(1,000 \mathrm{~h}+3,000 \mathrm{~h},+8,000 \mathrm{~h})$.

This series of papers describes the inspection on selected parts 
from the SOT assemblies. The boards were inspected to obtain whisker nucleation and length statistics. An inspection was done for each combination of alloy (SAC, Senju, Sunflower, Violet), surface finish (ENIG, ImmSn) and level of cleanliness (clean and contaminated). All or portions of the following short hand may be used to reference the configuration: (Finish-Solder-Board-PartReference Designator-Lead).

At the 4,000 inspection interval, the following quantities of randomly selected parts were inspected at $4,000 \mathrm{~h}$ for each combination:

- SOT3 - 6 components, 18 leads

- SOT5 - 2 components, 10 leads

- SOT6 - 2 components, 12 leads

At the 12,000 inspection interval, the same part locations for each combination were examined. The following quantities were inspected:

- SOT3 - 8 components, 24 leads

- SOT5 - 5 components, 25 leads

- SOT6 - 4 components, 24 leads

SEM photographs of all regions on the leads were taken at 100x magnification and all visible whiskers were counted to obtain whisker density. The whisker length criterion in JESD22A121A was used to perform the whisker length measurements [13] in the SEM, except whisker nucleation sites having an aspect ratio of approximately one were included in the whisker count. Whiskers longer than 10 microns were measured.

A unique aspect of measuring whiskers on part solder joints is that nothing is planar and the sample must be continually rotated and tilted during the inspection. As the stage is tilted, the whisker length appears to increase until the SEM inspection azimuth angle is perpendicular to the whisker. Further tilting results in the whisker beginning to appear shorter. In the present work, the reported whisker length measurements are conservative. During the length measurement procedure, the SEM inspection azimuth axis was adjusted to be aligned to within $\sim 30$ degrees from perpendicular to the whisker. The SEM axis misalignment from the whisker normal results in a potential whisker length under-reporting of up to 15 percent as shown in Figure 3. All whisker dimensions are reported in microns.

The whisker location was documented in an effort to understand patterns related to the underlying metallurgy. The locations are defined in Figure 4; the surface areas of each joint (lead, pad, and solder joint fillet) with respect to locations obtained via the image post processing are provided in Table 3. These surface areas were used in density calculations and were previously determined in earlier SERDP work [9]. In the present experiments, all whisker growth in region 2 occurred where the solder was thin, unless otherwise noted. Whisker diameter was also measured in the SEM. In addition, the whisker growth angle was approximately measured as shown in Figure 5.

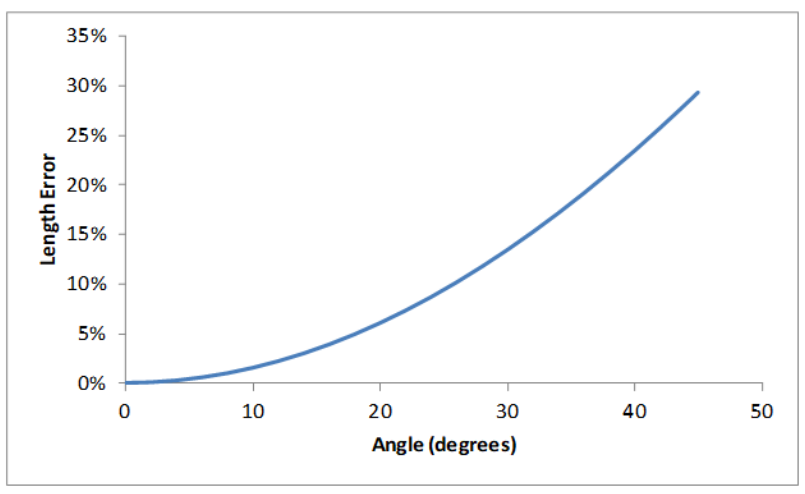

Figure 3: Whisker length measurement error estimate.

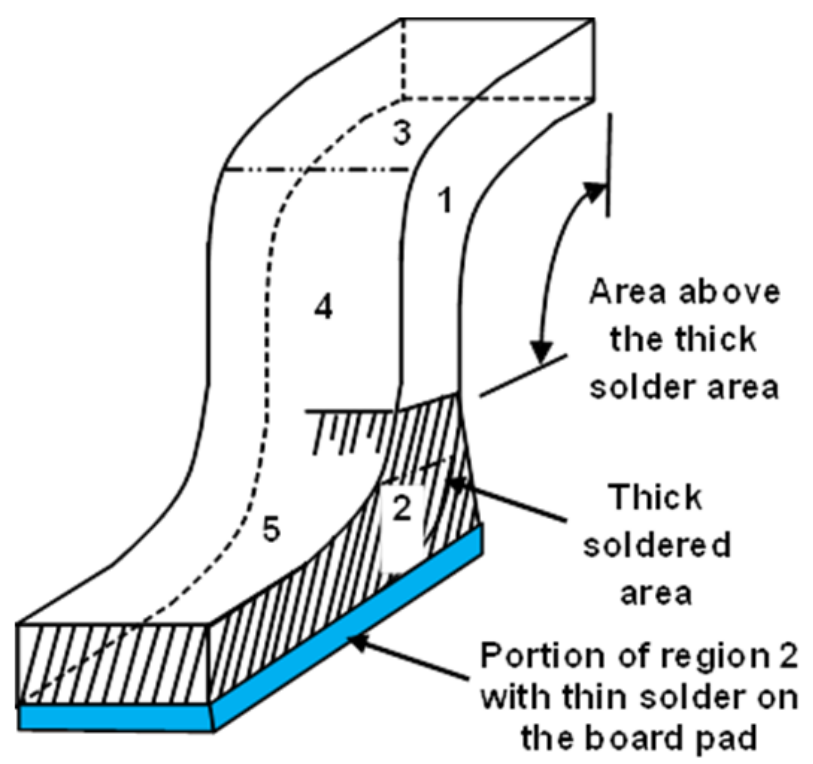

Figure 4: Whisker location definition. The hatched region 2 indicates the thick solder region on the lead and includes the thinner solder that wet onto the board pad. Areas 1, 3, 4 and 5 represent the thin solder or tin region above the thick solder area.

Table 3: Computed areas for SOT whisker growth locations $\left(\mathrm{mm}^{2}\right)$.

\begin{tabular}{|c|c|c|c|}
\hline Location & SOT-3 & SOT-5 & SOT-6 \\
\hline 1 & 0.086 & 0.187 & 0.116 \\
\hline 2 & 0.572 & 0.573 & 0.358 \\
\hline 3 & 0.066 & 0.054 & 0.036 \\
\hline 4 & 0.066 & 0.212 & 0.117 \\
\hline 5 & 0.314 & 0.241 & 0.133 \\
\hline Total & 1.104 & 1.267 & 0.760 \\
\hline
\end{tabular}




\section{$90^{\circ}$}

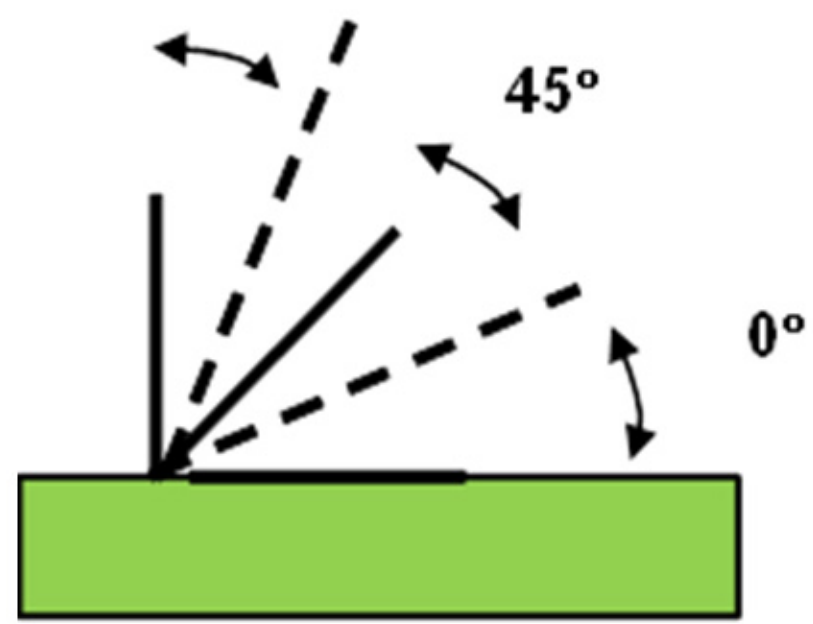

Figure 5: Whisker angle measurement definition.

\section{INSPECTION RESULTS}

\section{0 and 4000 hour inspections}

At the 1000 hour inspection, the cleaned boards had no whisker growth. The contaminated assemblies demonstrated growth of several small whiskers; the longest observed was 12 microns in length and was found on a SOT-5 component assembled using Sunflower paste on immersion tin finish.

After 4000 h, only a few whiskers were observed on contaminated assemblies. Cleaned assemblies did not grow any whiskers. No whiskers failed JESD Class 2. The longest whisker was on ImmSnSAC 305-SOT3, and was 29.5 microns in length and was hollow. Only four whiskers greater than 10 microns were measured; the only one that was not hollow was 11.9 microns in length, on ImmSn-Senju-SOT3. The longest whisker from the 1000 hour screening inspection was not observed in the 4000 hour screening inspection because a different set of parts were inspected.

\section{$12,000 \mathrm{~h}$ inspection}

\section{General Observations}

More whiskers were observed on contaminated assemblies than cleaned assemblies, and a larger proportion of parts/leads on ImmSn assemblies had whiskers compared with ENIG (Figure 6). For both cleaned and contaminated assemblies, a larger fraction of the inspected parts and leads assembled with Bi-bearing alloys (particularly Violet and Sunflower) demonstrated whisker growth than those assembled with SAC 305. Notably, for cleaned ENIG assemblies, whiskers were only observed on Sunflower, and on cleaned ImmSn assemblies, the proportion of parts/leads with whiskers increased with Bi content. A similar trend was observed on contaminated assemblies.
Whisker Length

The vast majority of whiskers greater than 10 microns in length were on contaminated parts - only one such whisker (14.3 microns) was observed on a cleaned assembly (ImmSn, Violet, SOT5, at L3 (Location 3, ref. Figure 19 in Part 1).

On contaminated ImmSn, two whiskers were measured which failed JESD201 for temperature/humidity storage. These measured $98.4 \mu \mathrm{m}$ and $79.3 \mu \mathrm{m}$ respectively and were found on SAC and Senju SOT-3 parts, respectively. Long whiskers on SOT-3 also occurred on the high temperature/humidity samples from our earlier work [9]. All alloys and parts showed comparable ranges in measured whisker length other than a few outliers such as those mentioned above - this indicates that whisker length is much more consistent on Bi-bearing alloys and the risk of developing a long whisker is reduced (Figure 7).

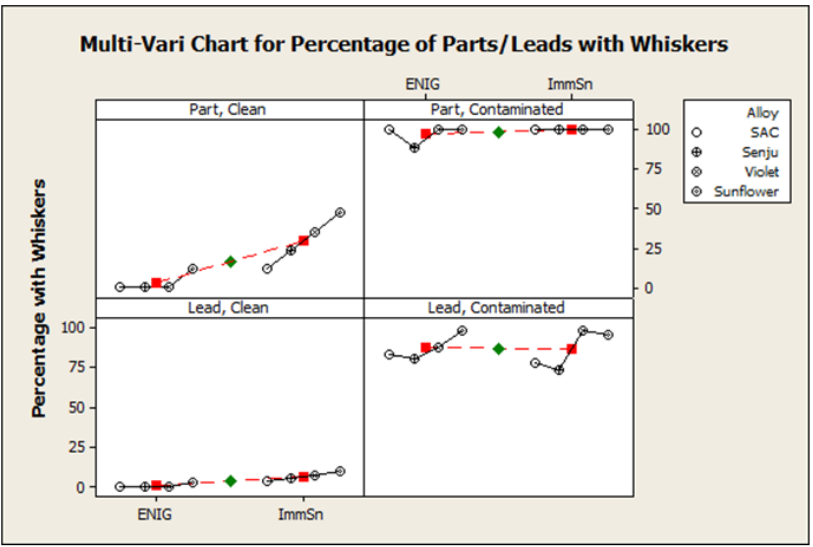

Figure 6: Percentages of inspected parts and leads with whiskers, by assembly cleanliness, surface finish, and alloy. 


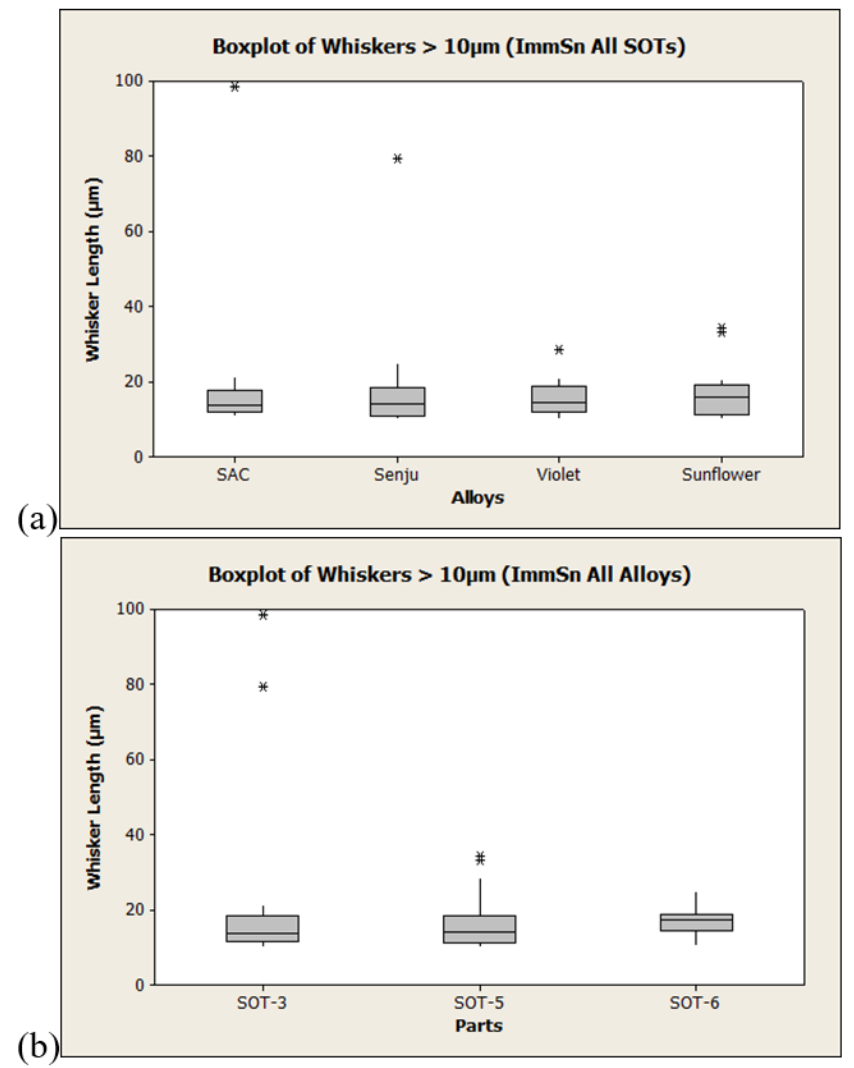

Figure 7: Statistical distribution of measured whiskers on the ImmSn finished boards; (a) alloys and (b) part types.

A very different trend was observed on ENIG (Figure 8). SAC showed very few whiskers longer than $10 \mu \mathrm{m}$ in length, and two whiskers on Violet SOT-5 parts failed the JESD standard (58.7 and $41.4 \mu \mathrm{m})$. Two additional whiskers on Sunflower SOT-3 $(39.7 \mu \mathrm{m})$ and Violet SOT-6 $(39.1 \mu \mathrm{m})$ nearly failed. Overall, fewer whiskers greater than $10 \mu \mathrm{m}$ in length were measured on ENIG than on ImmSn, however Sunflower had the most of the four alloys.

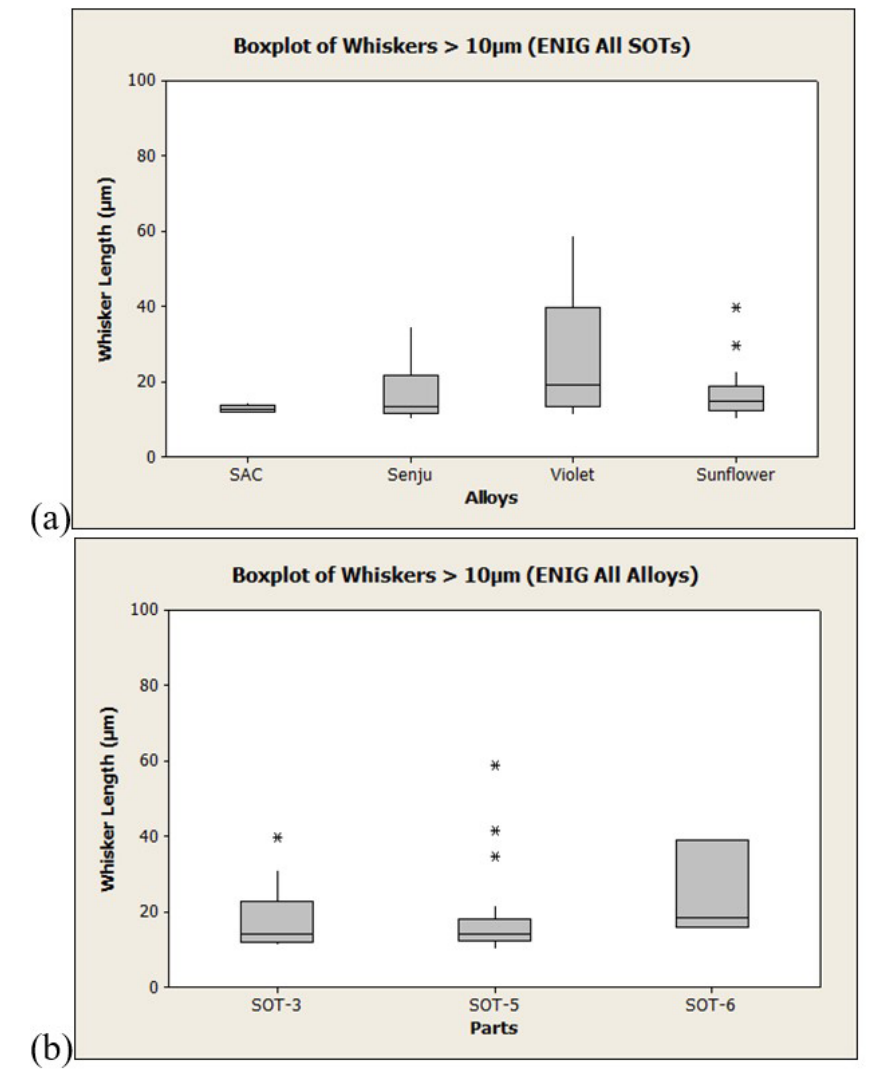

Figure 8: Statistical distribution of measured whiskers on ENIG finished boards; (a) alloys and (b) part types.

\section{Whisker Density}

Whisker density data is presented in a multiple-variable chart in Figure 9, with each panel consisting of combinations of surface finish and assembly cleanliness, with data points grouped by alloy with respect to location. Almost all whiskers on cleaned assemblies were present at L1, L3, and L4 and on SOT-5 and 6 parts; these leads are taller than SOT-3 leads and locations are near the top of the lead, where the solder is thinner, which are ideal conditions for whiskering. With respect to location and part type, all four alloys showed varying distributions of whisker density, most notably Violet and Sunflower for ImmSn. These 'spikes' in density can be explained by the localized concentration of whiskers on a small number of the total cohort of inspected leads. For example, the high density seen on Sunflower L1 is the result of 29 whiskers observed on one SOT-5 lead, 2 whiskers on another SOT-5 lead, and zero whiskers on the remaining 23 leads. Similar trends occurred for Violet; in both cases the leads with high whisker count were heavily corroded (Figure 10, also seen in Part 1). It is suspected that the contamination/corrosion may be the result of handling between chamber exposures. However, there are times when high whisker density occurred on the clean assembly with little or no incidental contamination (Figure 20 in Part 1 showing Imm SnSunflower-SOT5-U18 lead 4).

It is recommended that either the exposure time be increased to grow more whiskers, or a larger number of parts/leads be inspected for more meaningful data analysis of the cleaned assemblies. 


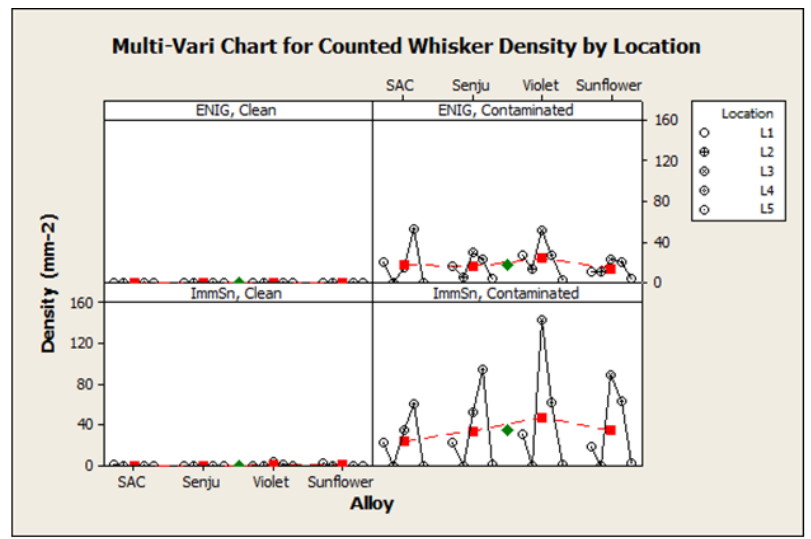

Figure 9: Whisker density by location, organized by assembly cleanliness, surface finish, and alloy.
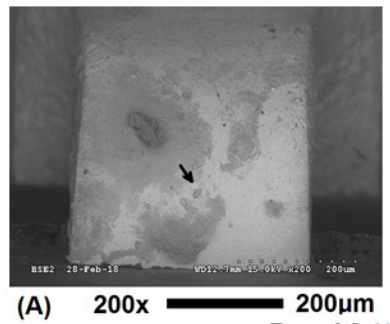

Board 2 U11 Lead 5

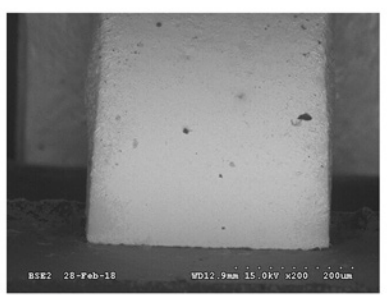

(C) 200x Board 2 U11 Lead 4

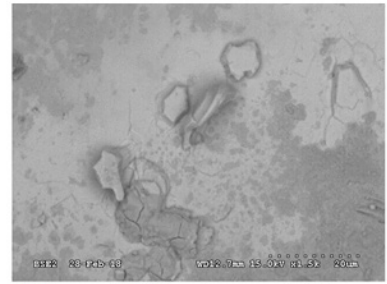

(B) $1500 x=20 \mu \mathrm{m}$

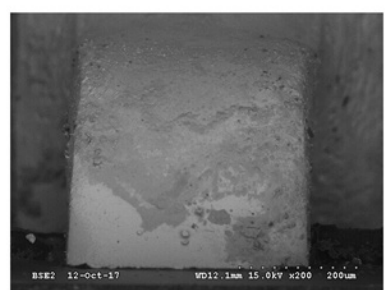

(D) 200x Board 2C U30 Lead 4
Figure 10: High whisker growth and corrosion on a cleaned assembly on a Violet soldered SOT5 lead on an ImmSn board, corresponding to the large spike in Figure 10. (A) Overview of lead, (B) whisker growth near the arrow in A, (C) adjacent lead with no corrosion or contamination, and (D) typical lead corrosion and whisker growth on a purposely contaminated assembly.

Similarly to the cleaned assemblies, whiskers were found almost exclusively on L1, L3 and L4 on contaminated ImmSn assemblies. The trend in density with respect to location varied between alloys. For SAC and Senju, the higher whisker density was on L4, and for Violet and Sunflower, the highest whisker density was on L3. Minor differences in density between the alloys are observed for L1 and L4 (other than Senju L4). Examination of Alloy-Part-Location plots with respect to whisker density did not explain these differences for each alloy, different part types were more favorable to whisker. It can be said that there are many competing processes taking part in these samples which make interpretation of the results difficult.
Two significant observations can be made comparing the ENIG result to the ImmSn result - fewer whiskers overall were seen on ENIG, and on the Bi-bearing alloys, appreciable whiskering was observed on L2 and L5, which did not show any whiskers on ImmSn. This may be a corrosion effect exclusive to the ENIG finish and is discussed below. In addition, a greater ratio in density between L3 and L4 was observed for the Bi-bearing alloys.

There appears to be a shift in the density difference between lead frame materials (Alloy 42 and Cu194) as the Bi content in the alloy increases (Figure 11). On both ImmSn and ENIG assemblies, higher densities are observed on Cu194 for SAC 305. Generally, Bi-bearing alloys demonstrate slightly higher density on Alloy 42 compared to SAC, and the whisker density on Cu194 is lower. $\mathrm{ImmSn}$ Senju is one interesting exception - density is higher than on any other combination of alloy and lead frame for ImmSn. For Violet and Sunflower, Alloy 42 demonstrated higher whisker density than Cu194, the opposite to what was seen for SAC.

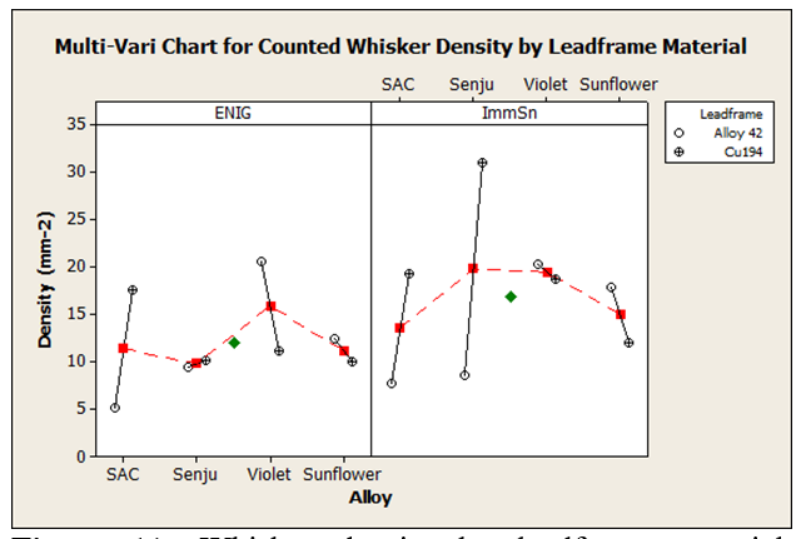

Figure 11: Whisker density by leadframe material, organized by surface finish and alloy.

Whisker density was calculated for each lead and these values (except densities of zero) are plotted in Figure 12 (ENIG) and Figure 13 (ImmSn), for each alloy and plot type, and fitted to a lognormal distribution. Statistical results from these distributions are given in Table 4 (ENIG) and Table 5 (ImmSn).

Definitions of the parameters are as follows:

- N: Number of leads with a whisker density.

- Location: Indicative of the median (log scale) whisker density.

- Scale: Indicative of the distribution of data (log scale). A larger value indicates a wider spread in whisker density across the sampled leads.

- AD (Anderson-Darling statistic): Indicative of how well the data fits the lognormal distribution. A larger value indicates a poorer fit. 


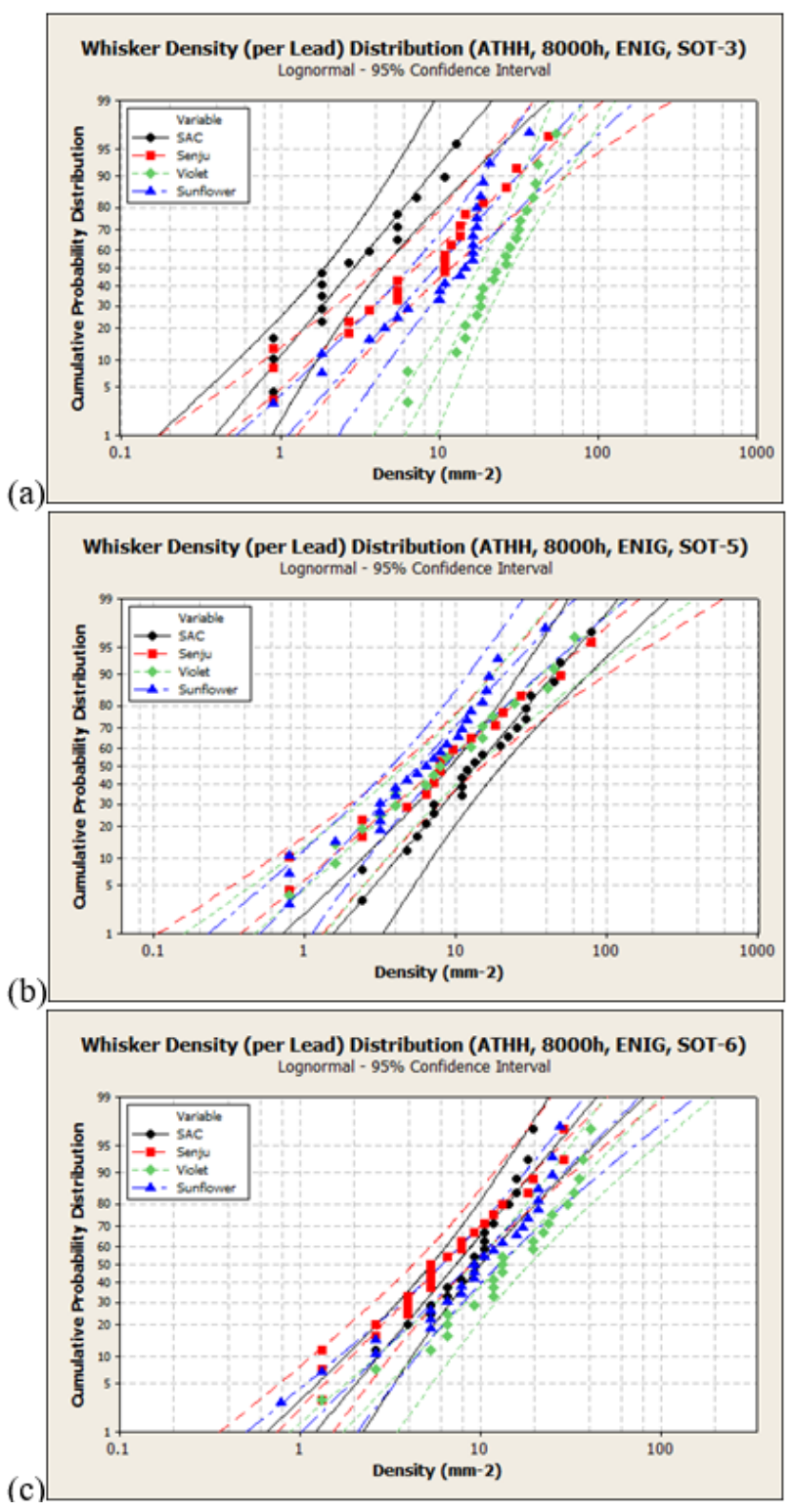

Figure 12: Lognormal probability plots of whisker density on a per lead basis, for ENIG-finished assemblies. SOT-3 (a); SOT-5 (b); SOT-6 (c).

Table 4: Lognormal Distribution Parameters (ENIG)

\begin{tabular}{|c|c|c|c|c|c|} 
Part & Alloy & $\mathbf{N}$ & Location & Scale & AD \\
\hline \multirow{4}{*}{ SOT-3 } & SAC 305 & 16 & 1.06 & 0.86 & 0.498 \\
\cline { 2 - 6 } & Senju & 20 & 1.96 & 1.17 & 0.501 \\
\cline { 2 - 6 } & Violet & 22 & 3.10 & 0.56 & 0.423 \\
\cline { 2 - 6 } & Sunflower & 23 & 2.26 & 0.93 & 1.439 \\
\hline \multirow{4}{*}{ SOT-5 } & SAC 305 & 22 & 2.60 & 0.94 & 0.180 \\
\cline { 2 - 6 } & Senju & 16 & 2.06 & 1.31 & 0.219 \\
\cline { 2 - 6 } & Violet & 19 & 2.06 & 1.21 & 0.144 \\
\cline { 2 - 6 } & Sunflower & 25 & 1.72 & 1.03 & 0.429 \\
\hline \multirow{4}{*}{ SOT-6 } & SAC 305 & 23 & 1.99 & 0.77 & 0.784 \\
\cline { 2 - 6 } & Senju & 23 & 1.82 & 0.91 & 0.252 \\
\cline { 2 - 6 } & Violet & 23 & 2.57 & 0.87 & 0.484 \\
\cline { 2 - 6 } & Sunflower & 24 & 2.28 & 0.80 & 0.477 \\
\hline
\end{tabular}

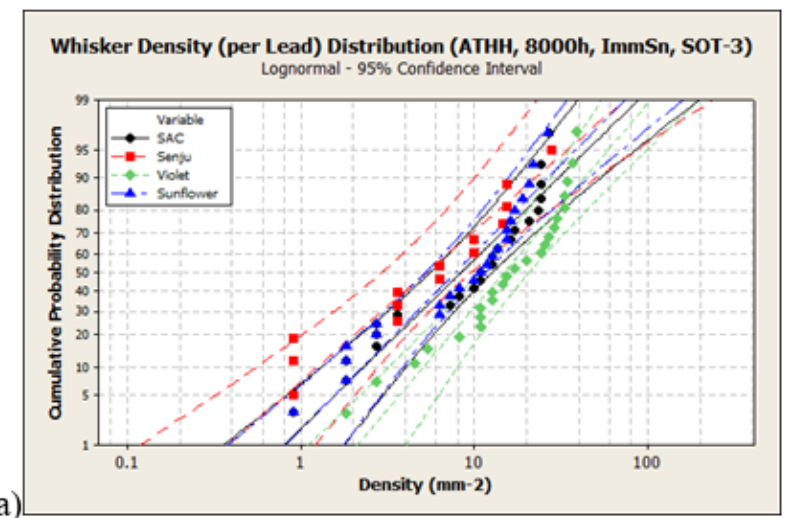

(a)

Whisker Density (per Lead) Distribution (ATHH, $8000 \mathrm{~h}$, ImmSn, SOT-5) Lognormal - $95 \%$ Confidence Interval

(b)

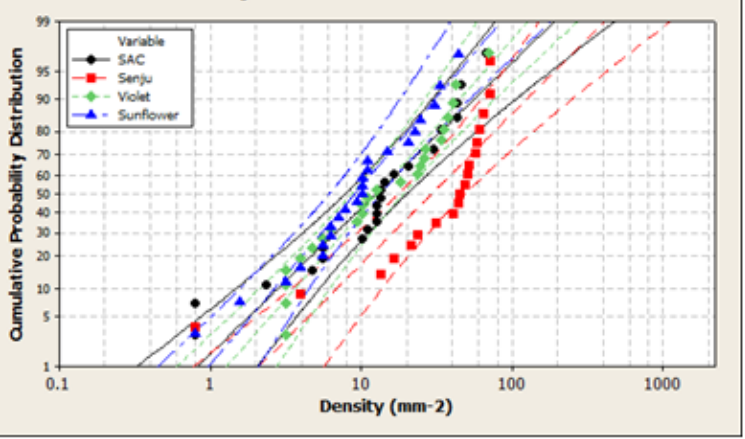

Whisker Density (per Lead) Distribution (ATHH, 8000h, ImmSn, SOT-6) ognormal - $95 \%$ Confidence Interval

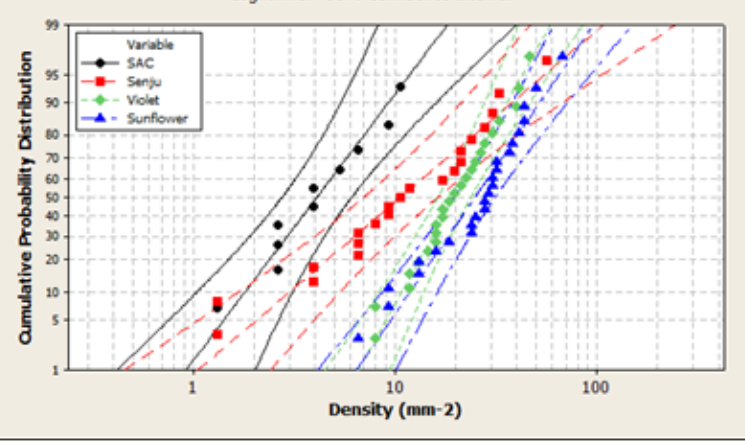

Figure 13: Lognormal probability plots of whisker density on a per lead basis, for ImmSn-finished

Table 5: Lognormal Distribution Parameters (ImmSn)

\begin{tabular}{|c|c|c|c|c|c|} 
Part & Alloy & $\mathbf{N}$ & Location & Scale & AD \\
\hline \multirow{4}{*}{ SOT-3 } & SAC 305 & 23 & 2.13 & 1.01 & 0.924 \\
\cline { 2 - 6 } & Senju & 14 & 1.67 & 1.13 & 0.528 \\
\cline { 2 - 6 } & Violet & 24 & 2.70 & 0.84 & 0.733 \\
\cline { 2 - 6 } & Sunflower & 23 & 2.05 & 0.97 & 1.002 \\
\hline \multirow{4}{*}{ SOT-5 } & SAC 305 & 24 & 2.53 & 1.17 & 0.754 \\
\cline { 2 - 6 } & Senju & 19 & 3.38 & 1.13 & 1.800 \\
\cline { 2 - 6 } & Violet & 24 & 2.55 & 0.99 & 0.600 \\
\cline { 2 - 6 } & Sunflower & 23 & 2.20 & 0.96 & 0.344 \\
\hline \multirow{4}{*}{ SOT-6 } & SAC 305 & 10 & 1.40 & 0.64 & 0.243 \\
\cline { 2 - 6 } & Senju & 21 & 2.36 & 0.99 & 0.375 \\
\cline { 2 - 6 } & Violet & 24 & 2.98 & 0.47 & 0.154 \\
\cline { 2 - 6 } & Sunflower & 24 & 3.21 & 0.58 & 0.599 \\
\hline
\end{tabular}


Overall, the density data demonstrates varying degrees of fit to the lognormal distribution. Several observations that can be made about these probability plots are as follows:

- Generally, a wider spread in densities can be seen on Cu194 leads (SOT-5) than Alloy 42 leads. Both lead materials show about the same wellness of fit to the lognormal distribution, overall.

- Overall, ENIG shows a slightly wider spread in density (across all parts/alloys) and fits the lognormal distribution slightly better than ImmSn.

- Several data sets show extremely poor fit to the lognormal distribution (AD > 1). These are ENIG, SOT-3, Sunflower (Figure 12a); ImmSn, SOT-3, Sunflower (Figure 13a); and ImmSn, SOT-5, Senju (Figure 13b). These have AD values of 1.439, 1.002, and 1.800 , respectively. The latter shows high average whisker density (Figure 11) - this may be caused by the uncharacteristically high number of leads with high whisker density.

- No clear trends can be seen with respect to alloy, considering these distributions.

\section{Whisker Diameter and Angle}

Boxplots showing the distribution of average whisker diameter for the different alloys and board finishes is given in Figure 14. If a whisker diameter changed over its length, the average of the minimum and maximum diameter was reported. It is observed that diameter is not largely dependent on alloy, particularly for ImmSn, though for both finishes, the median whisker diameter is slightly larger on the alloy with higher Bi content (Violet and Sunflower). Overall, for both ENIG and ImmSn, the diameter distributions do not appear to be statistically significant between alloys. The overall average diameter for the ENIG board finish is 2.6 microns and for the $\mathrm{ImmSn}$ is 3.5 microns.

Scatter plots showing the relationship between whisker length and diameter are given in Figure 15. Generally, very little correlation is observed, save ENIG-Senju and ImmSn-SAC. The longest whiskers were between two and eight microns in diameter.

The count of whisker growth angles is summarized in Figure 16. For the ImmSn finish, the majority of the whiskers had an angle of zero degrees, which means that the growth angle was relatively shallow (e.g. less than $\sim 20-25$ degrees as defined in Figure 5).

The complete set of data from the whisker inspection of the SOT assemblies after 12000 hours is given in the appendices of the original version of this paper, published at the 2018 SMTA ICEET conference.

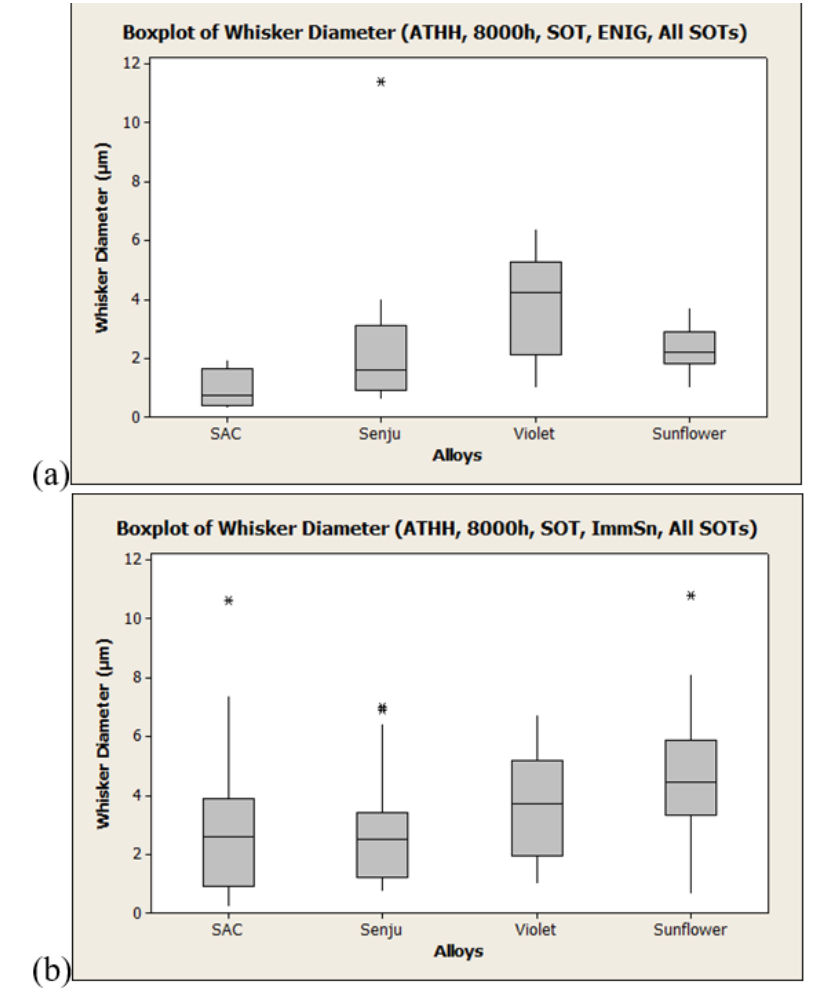

Figure 14: Statistical distribution of measured whisker diameters on ENIG (a) and ImmSn (b) finished boards, by alloy

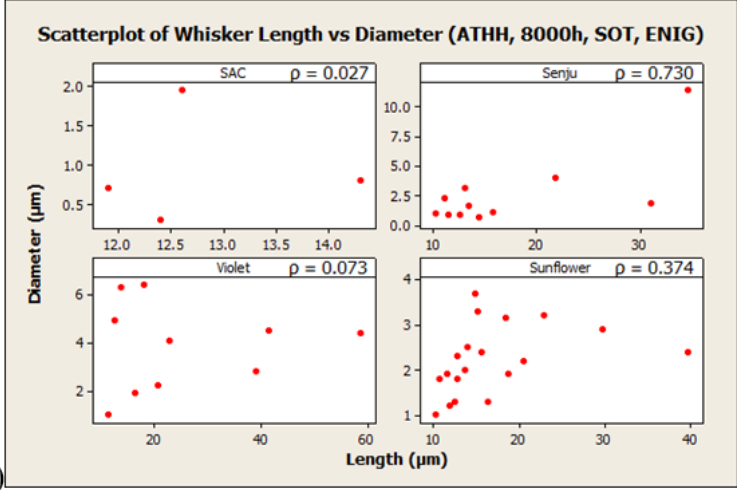

(a)

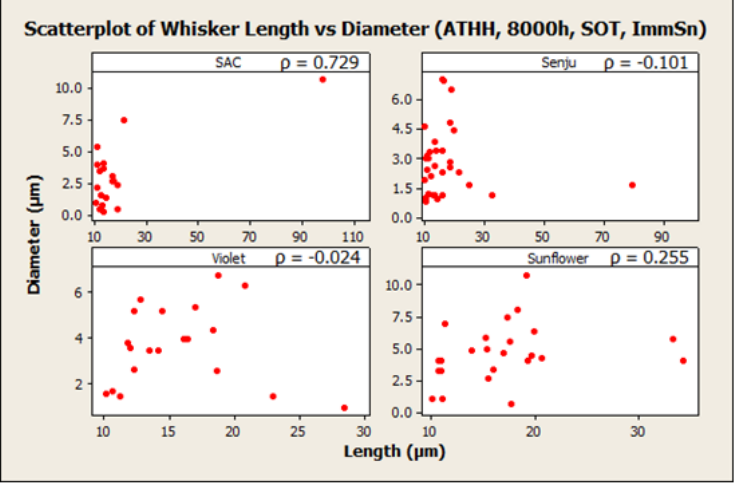

Figure 15: Whisker diameter versus length for the SAC, Senju, Sunflower and Violet alloys, with correlation coefficients ; (a) ENIG and (b) ImmSn. 
(a)

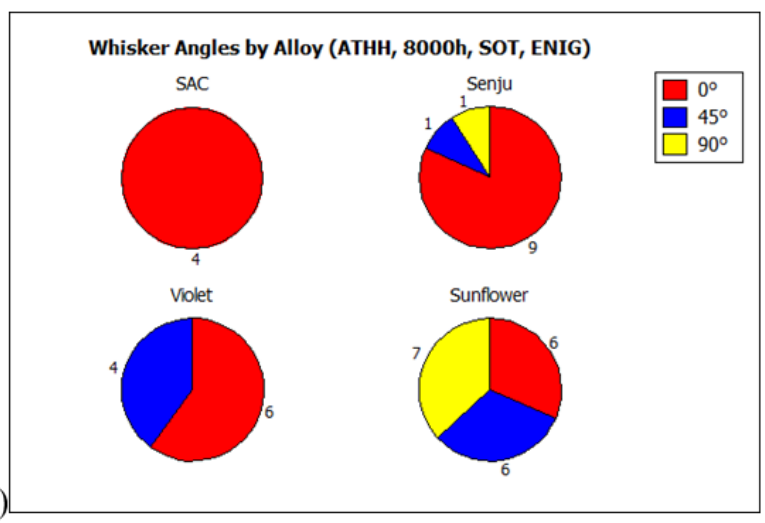

Whisker Angles by Alloy (ATHH, 8000h, SOT, ImmSn)
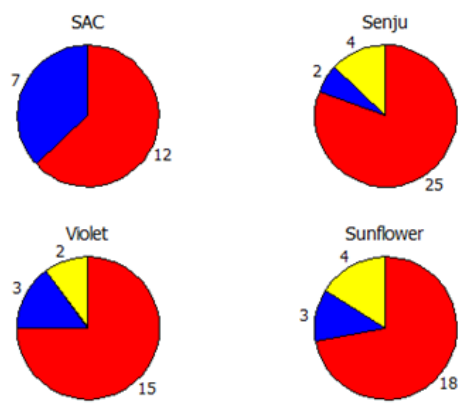

(b)

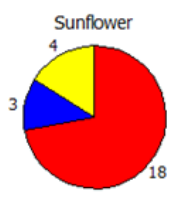

Figure 16: Count of whisker angle incidence for the SAC, Senju, Sunflower and Violet alloys; (a) ENIG and (b) ImmSn.

\section{DISCUSSION}

\section{Role of Bi in Whiskering}

After reflow, Bi forms a supersaturated solid solution with Sn. Over time, Bi will precipitate out of solution, forming small particles. The solid solubility of $\mathrm{Bi}$ in $\mathrm{Sn}$ is roughly $2 \mathrm{wt} \%$; the higher the $\mathrm{Bi}$ content in the alloy, the greater volume fraction of Bi precipitates. In addition, the $\mathrm{Bi}$ precipitates become more homogenously distributed through the alloy over time [14], likely due to continuous dissolution and re-precipitation at the exposure temperature $\left(25^{\circ} \mathrm{C}\right)$. Migration of $\mathrm{Bi}$ precipitates from the interdendritic spaces results in loss of dendritic structure of the primary Sn. In addition, larger Bi precipitates will not undergo dissolution/re-precipitation; rather they will remain out of solution and undergo Ostwald ripening (Dissolution of small grains in favor of growing larger grains) as some $\mathrm{Bi}$ migrates to the phase boundaries between the large particles and Sn matrix (Figure 17).

In addition, $\mathrm{Bi}$ precipitation induces the recrystallization of the Sn matrix [15] into a homogeneous, equiaxed grain structure (Figure 18). This is likely a result of density and crystal structure mismatch between the $\mathrm{Sn}$ and Bi phases (Table 6) - as $\mathrm{Sn}$ is softer and more ductile than $\mathrm{Bi}$, it will experience stress due this mismatch. Recrystallization is the result of the Sn matrix relieving this stress. It is believed that whisker nucleation and growth is analogous to recrystallization - while grain size in the bulk is restricted by neighboring grains, the free surface provides an opportunity for unhindered grain growth which results in a whisker. In SAC 305, whiskers are generally longer and sparser because the stress is higher in more localized regions. Adding $\mathrm{Bi}$ to the alloy causes a more distributed stress condition in the joint, resulting in more nucleation sites for whiskers. These whiskers, however, are substantially shorter and less of a reliability risk.

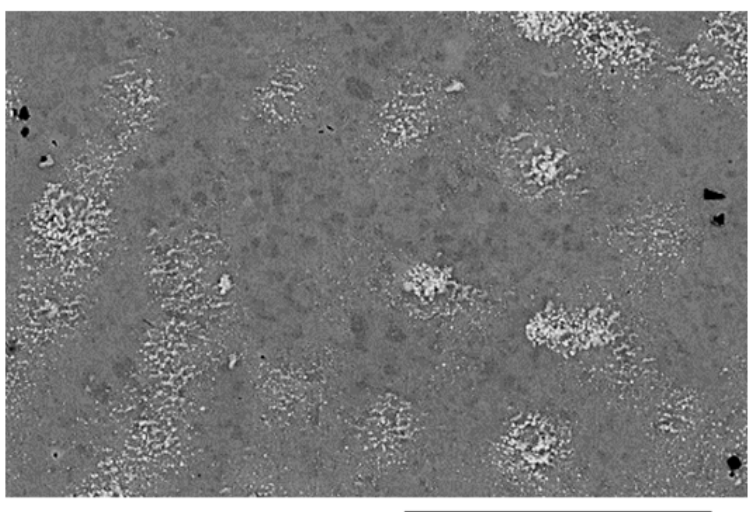

(a)

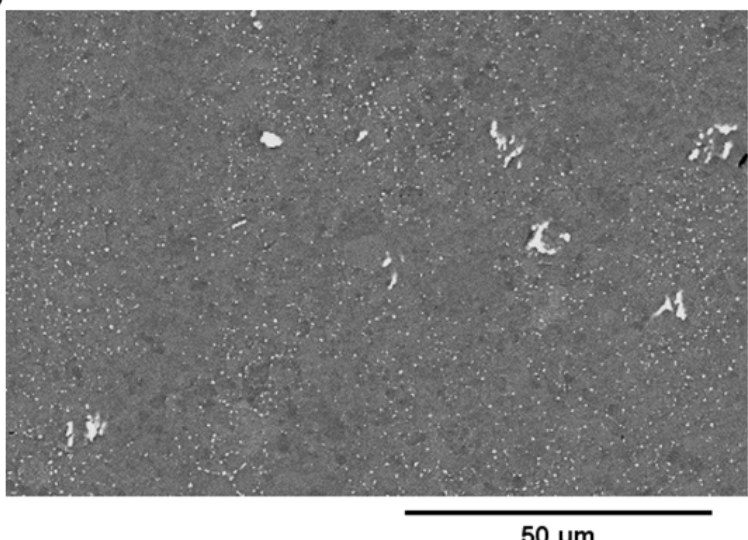

(b)

Figure 17: Evolution of microstructure of Sn-5Bi after aging at room temperature [14]; (a) As-cast and (b) after 168 days. With aging time, Bi precipitates become more evenly distributed and some precipitates undergo Ostwald ripening. 


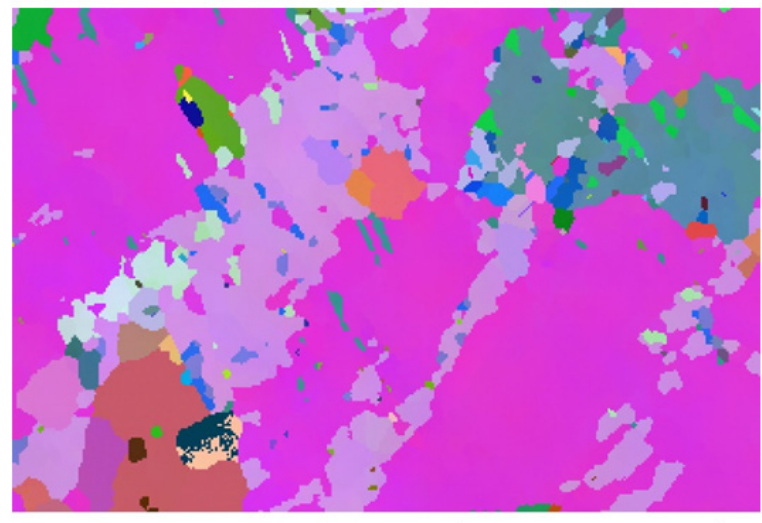

(a)

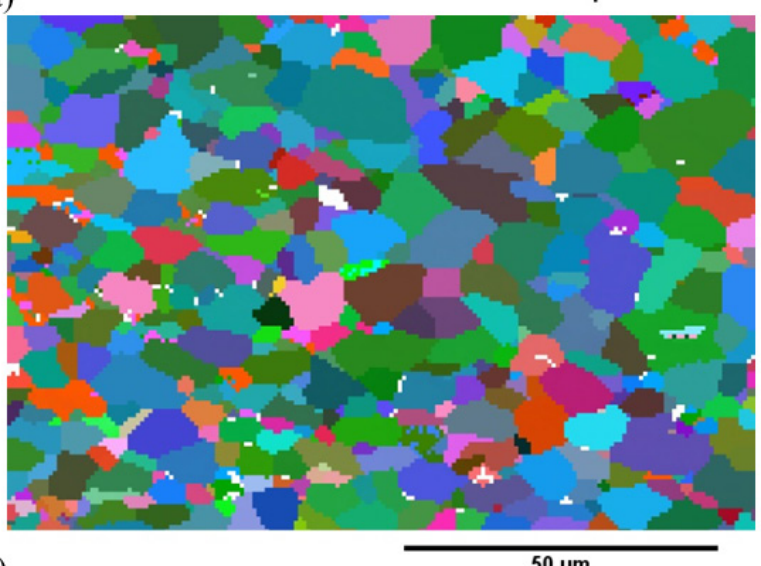

(b)

$50 \mu \mathrm{m}$

Figure 18: Recrystallization of Violet after aging [15]; (a) As cast and (b) after aging at $125^{\circ} \mathrm{C}$ for 100 hours.

Table 6: Density and crystal structure data for Sn and Bi.

\begin{tabular}{|c|c|c|}
\hline Metal & Density $\left(\mathbf{g} / \mathbf{c m}^{\mathbf{3}}\right)$ & Crystal Structure \\
\hline $\mathrm{Sn}$ & 7.27 & Body-centered tetragonal \\
\hline $\mathrm{Bi}$ & 9.78 & Rhombohedral \\
\hline
\end{tabular}

\section{Role of Bi in Corrosion}

The addition of $\mathrm{Bi}$ to the alloy may also exacerbate corrosion, which would result in an increase in whiskers. This would be prevalent in alloys with substantial Bi precipitation (Violet and Sunflower). Examination of the galvanic series (Table 7) indicates that $\mathrm{Bi}$ is more noble than $\mathrm{Sn}[16]$ and thus in a Sn-Bi couple, the $\mathrm{Sn}$ will preferentially corrode (as observed in Figure 19). The galvanic cell analysis is as follows:

\begin{tabular}{|c|c|c|}
\hline$\#$ & Half Reactions & $\begin{array}{c}\text { Standard Half } \\
\text { Cell Potential }(\mathrm{V})\end{array}$ \\
\hline 1 & $\mathrm{Bi}_{2} \mathrm{O}_{3}+3 \mathrm{H}_{2} \mathrm{O}+6 \mathrm{e}-\rightarrow 2 \mathrm{Bi}+6 \mathrm{OH}-$ & $-0.46 \mathrm{~V}$ \\
\hline 2 & $\mathrm{SnO}_{2}+2 \mathrm{H}_{2} \mathrm{O}+4 \mathrm{e}-\rightarrow \mathrm{Sn}+4 \mathrm{OH}-$ & $-0.945 \mathrm{~V}$ \\
\hline 3 & $\mathrm{Cu}_{2} \mathrm{O}+\mathrm{H}_{2} \mathrm{O}+2 \mathrm{e}-\rightarrow 2 \mathrm{Cu}+2 \mathrm{OH}-$ & $-0.36 \mathrm{~V}$ \\
\hline
\end{tabular}

Rearranging to combine Reactions 1 and 2 into Reaction 4, and 2 and 3 into Reaction 5:

\begin{tabular}{|c|c|c|}
\hline$\#$ & Reaction & $\begin{array}{c}\text { Standard Cell } \\
\text { Potential }(V)\end{array}$ \\
\hline 4 & $2 \mathrm{Bi} 2 \mathrm{O} 3+3 \mathrm{Sn} \rightarrow 4 \mathrm{Bi}+3 \mathrm{SnO} 2$ & $+0.485 \mathrm{~V}$ \\
\hline 5 & $2 \mathrm{Cu} 2 \mathrm{O}+\mathrm{Sn} \rightarrow 4 \mathrm{Cu}+\mathrm{SnO} 2$ & $+0.585 \mathrm{~V}$ \\
\hline
\end{tabular}

Table 7: Abridged galvanic series of metals in sea water [16]. The galvanic potential for Au was not included; the value for Pt is given as it behaves comparably to Au.

\begin{tabular}{|c|c|}
\hline Metal & $\begin{array}{c}\text { Median Potential } \\
\text { (V) (SCE Reference) }\end{array}$ \\
\hline Gold & +0.295 \\
\hline Copper & -0.141 \\
\hline Nickel & -0.172 \\
\hline Bismuth & -0.248 \\
\hline Tin & -0.671 \\
\hline
\end{tabular}

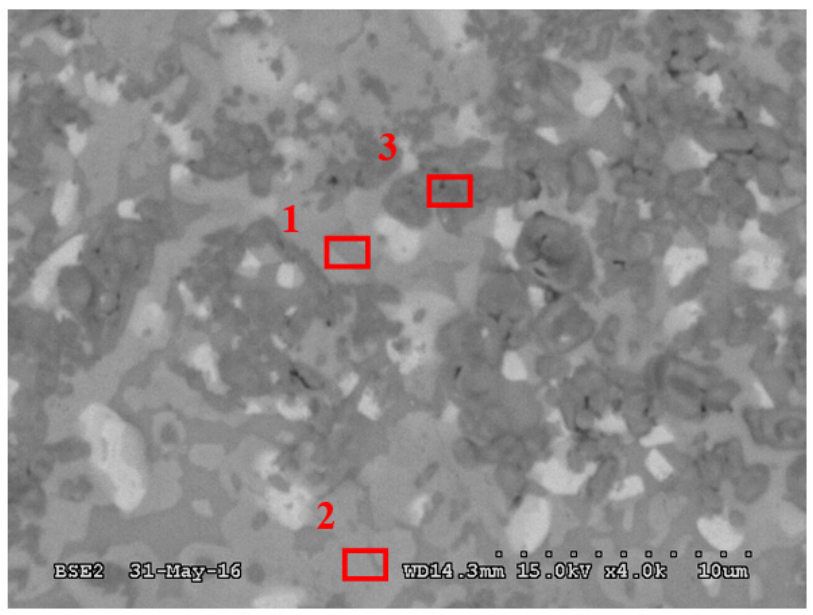

Figure 19: 4000h inspection showing corrosion between Sn and Bi on a cleaned SOT6 lead with Sunflower on an ENIG finished pad (4000x magnification). EDX locations are labelled; the bright white particles are $\mathrm{Bi}$.

The net standard cell potentials are positive, which suggests that the reactions will proceed to the right, and Sn will preferentially oxidize in a couple with either $\mathrm{Bi}$ or $\mathrm{Cu}$. It supports the SEM/ EDX results (Table 8) where corrosion of $\mathrm{Sn}$ occurred around $\mathrm{Bi}$ precipitates, and the lack of $\mathrm{Bi}$ in the outer oxide layer of the corroded whisker ( $\mathrm{Bi}$ is rejected from the growing oxide layer into the core of the whisker). Note if $\mathrm{SnO}$ instead of $\mathrm{SnO}_{2}(\mathrm{~V}=-0.10 \mathrm{~V})$ is used, the net cell potential is negative $(-0.36 \mathrm{~V})$, which would suggest that $\mathrm{Bi}_{2} \mathrm{O}_{3}$ and $\mathrm{Sn}$ will coexist rather than $\mathrm{SnO}$ and $\mathrm{Bi}$. Since this was not observed in the current EDX data, it is more likely that $\mathrm{SnO}_{2}$ is taking part (or predominant) in this galvanic cell.

In addition, phase boundaries (e.g. between $\mathrm{Sn}$ and $\mathrm{Bi}$ ) are more active than bulk material and are more susceptible to corrosion. 
Finally, the recrystallization of the alloy induced by Bi precipitation causes an increase in Sn grain boundaries, which are also high energy boundaries that are more susceptible to corrosion.

Table 8: Detailed EDX spectra for Figure 19.

\begin{tabular}{|c|c|c|c|}
\hline Element & pt 1 & pt 2 & pt 3 \\
\hline $\mathrm{C}$ & 7.34 & 6.40 & 7.80 \\
\hline $\mathrm{N}$ & 5.26 & 4.62 & 3.28 \\
\hline $\mathrm{O}$ & 6.31 & 5.11 & 5.11 \\
\hline $\mathrm{Si}$ & 0.00 & 0.00 & 1.21 \\
\hline $\mathrm{Ni}$ & 0.00 & 1.02 & 8.89 \\
\hline $\mathrm{Cu}$ & 0.00 & 0.00 & 13.33 \\
\hline $\mathrm{Sn}$ & 76.15 & 69.81 & 54.47 \\
\hline $\mathrm{Au}$ & 1.39 & 9.48 & 4.46 \\
\hline $\mathrm{Bi}$ & 3.55 & 3.56 & 1.45 \\
\hline
\end{tabular}

\section{Effect of $\mathrm{Au}$ in Corrosion on ENIG finish}

The galvanic series suggests that Au is more noble than all other species in the joint [16]. This fact, in addition to the Sn-Bi galvanic effect and increase in grain and phase boundary content in Bibearing alloys, may explain the increased whiskering on ENIG at L2 and L5 shown in Figure 9. These locations are close to the pad and thus likely richest in Au. Significantly fewer whiskers were seen in these locations for SAC, likely because the whisker-inducing effects of $\mathrm{Bi}$ were not present.

\section{SUMMARY AND CONCLUSIONS}

Several key takeaways from the statistical results of this study are as follows:

- On cleaned assemblies, generally a higher proportion of parts/ leads show whiskers as the Bi content is increased.

- On ImmSn, whiskers were generally shorter and more consistent on alloys with high Bi content (Violet and Sunflower), however the opposite is observed for ENIG.

- On cleaned assemblies and on contaminated ImmSn assemblies, whisker growth was restricted to regions with thin solder coverage, such as L1, L3 and L4.

- However for contaminated ENIG assemblies, while showing fewer whiskers than ImmSn, substantially more whiskers were observed on locations close to the pad (L2 and L5). This may be caused by an exacerbation of corrosion related to the nobility differences between the various species present at these regions (such as gold from the surface finish).

- Whisker diameter is not strongly correlated with whisker length or alloy type, however diameter is slightly larger for the higher-Bi alloys (Violet and Sunflower).
From a practical perspective, it is challenging to keep an initially clean assembly from getting incidental contamination that can promote whisker growth during the product life cycle. The typical practice of conformal coating a product helps reduce the risk of incidental contamination by providing an added barrier between the environment and the termination. It is for this reason that full coverage of conformal coating is desired for whisker mitigation.

The utilization of clean boards permits evaluation of the alloy impact on whisker formation. Contamination and corrosion may mask the effects of alloy additions and other growth mechanisms. In longer tests, where corrosion results in whiskers falling off or possibly becoming consumed by the corrosion products, it can also influence whisker density and length results.

It is important when studying whisker growth of solder joints that all the material interaction be considered. For ImmSn, there were more whiskers on the Bi-bearing alloys, but they were shorter in length and more kinked/curved than the SAC305 terminations. This is believed to represent a more even distribution of stress due to a greater number of small Sn grains as compared to the SAC alloy. However the opposite is observed for ENIG, suggesting that consideration of multiple mechanisms contributing to whiskering must be considered. This will be done in the third paper in this series.

\section{FUTURE WORK}

One follow-up paper is planned which supplements the work shown in this paper and in Part 1. In that paper (Part 3), more analytical work, including cross-section and EDX, of interesting features will be provided. In addition, screening inspection results from QFP and BGA boards will be shown, and the results from a detailed inspection of the latter will be included in a further future publication.

Further whisker mechanisms will be proposed and discussed, notably with respect to the role of $\mathrm{Bi}$ and $\mathrm{Au}$ in the corrosion of solder joints. In addition, an expansion to the previously discussed whisker 'sweet spot' concept, considering the effects of $\mathrm{Bi}$ on the stress state in solder joints and subsequent response of the microstructure, will be considered.

\section{ACKNOWLDEGEMENTS}

The authors would like to thank the Canadian ReMAP program, Russell Brush, Celestica, for the environmental testing, and Ivan Tan, Celestica, for the assembly.

\section{REFERENCES}

[1] GEIA-STD-0005-2, Standard for Mitigating the Effects of Tin Whiskers in Aerospace and High Performance Electronic Systems, SAE International, Warrendale, PA.

[2] P.T. Vianco, M.K. Neilsen, J.A. Rejent, and R.P. Grant, Validation of the Dynamic Recrystallization (DRX) Mechanism for Whisker and Hillock Growth on Sn Thin Films, Journal of Electronic Materials, Vol. 44, No. 10, 2015, pp. 4012 - 4034. 
[3] G.T. Galyon, Annotated Tin Whisker Bibliography and Anthology, IEEE Trans. Packag. Manuf. Vol. 28, No. 1, January 2005, pp. 94-122.

[4] J. Nielsen and T. Woodrow, The Role of Trace Elements in Tin Whisker Growth, Project WP1751 Final Report for the Strategic Environmental Research and Development Projects (SERDP), September 22, 2013.

[5] I. Yanada, "Electroplating of Lead-Free Solder Alloys Composed of Sn-Bi and Sn-Ag, Proc. Of the IPC Printed Circuits Expo, Long Beach USA: pp. S11-2 to S11-2-7, April 1998.

[6] S. Meschter, P. Snugovsky, Z. Bagheri, E. Kosiba, M. Romansky, J. Kennedy, L. Snugovsky, and D. Perovic, Whisker Formation on SAC305 Soldered Assemblies, JOM, vol. 66 no. 11, pp. 2320-2333, Nov. 2014 (DOI) 10.1007/s11837-014-1183-9, available on line at

http:/ / www.springer.com/home?SGWID=0-0-1003-0-0\&aqId= $2737780 \&$ download $=1 \&$ checkval $=$ c6d6cb73aec6cca572a5b064f23 $677 \mathrm{~b} 9$

[7] P. Snugovsky, S. Meschter, Z. Bagheri, E. Kosiba, M. Romansky, and J. Kennedy, Whisker Formation Induced by Component and Assembly Ionic Contamination, Journal of Electronic Materials, February 2012, Volume 41, Issue 2, pp 204223, available for download at http://link.springer.com/content/ pdf/10.1007\%2Fs11664-011-1808-5.pdf

[8] S. Meschter, P. Snugovsky, J. Kennedy, and Z. Bagheri , ReMAP Materials Project M2: High Temperature High Humidity Corrosion and Tin Whisker Evaluation of Bi containing Leadfree Alloys, International Conference on Soldering and Reliability, (ICSR) Toronto, Canada, May 10-11, 2016

[9] S. Meschter, Tin Whisker Testing and Modeling, Project WP1753 Final Report, U.S. DoD, EPA, DOE Strategic Environmental Research Programs (SERDP), November 2015, available for download at: https://www.serdp-estcp.org/ProgramAreas/Weapons-Systems-and-Platforms/Lead-Free-Electronics/ WP-1753

[10] S. Meschter, E. Ekstrom, P. Snugovsky, J. Kennedy, Z. Bagheri, and E. Kosiba, Strategic Environmental Research and Development Program (SERDP) Tin Whisker Testing and Modeling: Long Term Low Temperature High Humidity Testing, International Conference on Soldering and Reliability (ICSR), Toronto, Ontario, Canada; May 19-21, 2015.

[11] JESD201 Environmental Acceptance Requirements for Tin Whisker Susceptibility of Tin and Tin Alloy Surface Finishes, JEDEC Solid State Technology Association, Arlington, VA 2006

[12] S. Meschter, P. Snugovsky, J. Kennedy, Z. Bagheri, and E. Kosiba, Tin Whisker Testing: Low Stress Conditions, SMTA International Conference on Solder Reliability, Toronto, Ontario, Canada, 2012

[13] JESD22A121A Test method for measuring whisker growth on tin and tin alloy surface finishes, JEDEC Solid State Technology Association, Arlington, VA 2000.
[14] A. Delhaise, D. Perovic, P. Snugovsky, "The Effects of Aging on the Microstructure and Mechanical Properties of Bi-Containing Sn-Rich Alloys," J. Surface Mount Technology, 30, 2 (2017), pp. 21-27

[15] A. Delhaise, P. Snugovsky, I. Matijevic, J. Kennedy, M. Romansky, D. Hillman, D. Adams, S. Meschter, J. Juarez, M. Kammer, I. Straznicky, L. Snugovsky, D. Perovic, "Thermal Preconditioning, Microstructure Restoration, and Property Improvement in BiContaining Solder Alloys," J. Surface Mount Technology, 31, 1 (2018), pp. 33-42

[16] J.A. Smith, P.E. Groover, T.J. Lennox Jr., M.H. Peterson, "The Electrochemical Potential of High Purity Metals in Seawater," Naval Research Laboratory Memorandum Report 2187 (November 1970)

\section{BIOGRAPHIES}

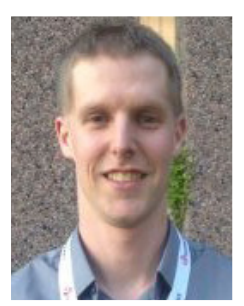

André Delhaise is a metallurgist at Celestica, Inc., and is actively involved in several projects in association with the Refined Manufacturing Acceleration Process (ReMAP), which is a Canadian-led consortium of academic and industry partners focused on the commercialization of novel manufacturing technologies and processes. $\mathrm{He}$ is also involved in the iNEMI 3rd generation $\mathrm{Pb}$-free alloy characterization effort as well as the Pb-free Risk Management (PERM) group. André is also currently a $\mathrm{PhD}$ Candidate in the Department of Materials Science \& Engineering at the University of Toronto, specializing in the metallurgy of bismuth-containing lead-free solders, under the supervision of Dr. Doug D. Perovic. He holds a Bachelor of Applied Science (BASc) degree from the same department, obtained in 2013. André was awarded the 'Best of Proceedings' award at the SMTA International Conference in 2017, and has published several papers in refereed journals such as the Journal of Electronic Materials (JEM).

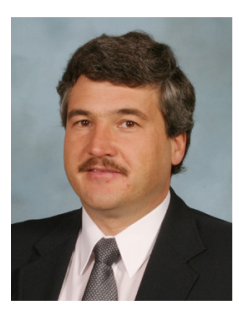

Dr. Stephan Meschter has over 30 years of experience in advanced packaging, failure analysis, and reliability testing of electronic assemblies at BAE Systems Electronic Systems in Endicott, NY. He has designed and evaluated electronic assemblies for power, flight and jet engine control systems used in spacecraft, aircraft and ground vehicles. Starting in 2004, Stephan began evaluating the commercial lead-free materials transition impact to high-reliability, high-performance aerospace and defense electronic systems. He was a member of the 2009 U.S. DoD Lead-free Electronics Manhattan Project team that published a set of best practices to mitigate the risks associated with $\operatorname{Lead}(\mathrm{Pb})$ free electronics usage in high performance DoD systems. Since 2010, Stephan has worked with SERDP on lead-free tin whisker formation research and short circuit risk mitigation using enhanced polymer conformal coatings. He earned a bachelor's in mechanical engineering from the University of Hartford in Hartford CT in 1984, and he holds both a master's degree (1987) and a doctoral 
degree (2001) in Mechanical Engineering from the State University of New York in Binghamton, NY. Stephan currently participates in the IPC Lead $(\mathrm{Pb})$-free Electronics Risk Management (IPC-PERM) Council and is currently supporting revision of several SAE GEIA Lead-free Aerospace and Defense risk management standards.

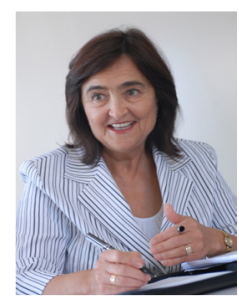

Polina Snugovsky recently served as Principal Engineer - Chief Metallurgist at Celestica. Polina was an invited subject matter expert participant in the $2009 \mathrm{~Pb}$-free Manhattan Project tasked with the risk assessment of Pb-free electronics in Aerospace and DoD applications. Polina was an active participant in the Pbfree electronics in aerospace project group (AIA PERM) - American Institute of Aeronautics. She was the principal investigator of two U.S. DoD Strategic Environmental Research and Development Projects (SERDP) that are examining corrosion induced whisker growth and manufacturing mitigation. She has also actively participated in NASA DoD projects. Dr. Snugovsky graduated from the State Metallurgical Academy of Ukraine and received her Ph.D. in Metallurgy, and subsequently in 1985 she earned the higher level Doctoral degree in Metallurgy and Material Science. Before she joined Celestica in 1996, she was a full professor in the department of physical metallurgy of the State Metallurgical Academy of Ukraine. She has published over 160 papers and patented new materials and processes. Polina holds several Outstanding Technical Achievement Awards, including two from Celestica and received Best International Conference Papers awards at SMTA2006, APEX2007, APEX2009, APEX2010, APEX2013 and APEX2014. In 2012 she received SMTA Member of Technical Distinction Award.

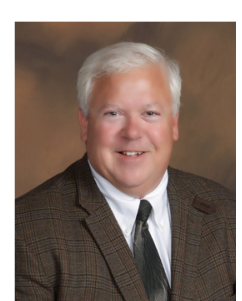

Jeff Kennedy is currently the Strategy and Business Development Manager at ZESTRON Americas. Prior to that he directed Celestica's advanced technology strategy and development initiatives, including the design and implementation of technology roadmaps for the Industrial and A\&D sectors. Jeff has more than 30 years of experience in system integration, process development, PWB fabrication, and packaging in the microelectronics industry. He has engineering and management experience working within mainframe computer industry, microcircuit wire bonding and flip chip, PWB fabrication and laminate packaging substrates, and the last 16 years in contract electronics assembly. Jeff is a past President of SMTA and is an active member of both IPC \& IMAPS. 